\title{
Transformation from manufacturing process taxonomy to repair process taxonomy: a phenetic approach
}

\author{
Umair Raza ${ }^{1} \cdot$ Wasim Ahmad ${ }^{1} \cdot$ Atif Khan $^{2}$ \\ Received: 19 May 2017 / Accepted: 13 September 2017 / Published online: 15 February 2018 \\ (C) The Author(s) 2018. This article is an open access publication
}

\begin{abstract}
The need of taxonomy is vital for knowledge sharing. This need has been portrayed by through-life engineering services/ systems. This paper addresses this issue by repair process taxonomy development. Framework for repair process taxonomy was developed followed by its implementation. The importance of repair process taxonomy has been highlighted.
\end{abstract}

Keywords Through-life engineering $\cdot$ Knowledge sharing

\section{Introduction}

Aerospace OEM including Rolls Royce, GE aviation, etc. had been selling their equipment along with after-sales service; however, shrinkage in business and severe environmental laws compelled these OEM to switch from aftersales service to a new strategy named as through life engineering. So customer has to afford huge maintenance cost which resulted in limited expansion of business. So for adopting through-life engineering business strategy, repair policy has to be implemented. The problem in solution is that companies do not have repair knowledge available as previously companies were outsourcing their repair job. In this scenario, a solution to these problems is suggested that a common platform is needed to develop where repair designers, repair team may co-ordinate with each other to mitigate issues regarding repairing components. A pictorial representation regarding these issues between repair and design team has been presented in Fig. 1. Second there is a need to differentiate between repair processes and manufacturing processes as there is a significant difference exists between repair processes and manufacturing processes from application point of view. For example, welding is a

Umair Raza

umair_raza2001@yahoo.com

1 Industrial Engineering Department, University of Engineering and Technology, Taxila, Pakistan

2 Mechanical Engineering Department, National University of Science and Technology, Islamabad, Pakistan joining process in manufacturing taxonomy; however, welding is a material addition process in repair process taxonomy.

This paper concentrates on repair process taxonomy development of mechanical components to promote repair technology. Repair process taxonomy will help in reducing complexity. As well as identifying similarities and differences among repair processes, helps in clear understanding of repair field to overcome confusion and difficulties in exploring (Bolden et al. 1997). Repair processes coding as well as exploration of knowledge domains can be easily done (Geisler 2006). Taxonomies are very costly to maintain in contrary to value when it is detailed at large (Whittaker and Breininger 2008). Successful taxonomy has following attributes which includes conciseness, inclusiveness, comprehensiveness and enhanceable (Nickerson et al 2009).

This research work focuses on developing repair process taxonomy of mechanical components to overcome the problem of repair designer as well as repair team. This paper has been divided as follow: "Literature review" gives a brief of literature review carried out regarding taxonomy applied in different fields and taxonomy development methods in different field has been explored. Manufacturing processes employed in repairing of mechanical components has been sort out. "Research methodology" thoroughly describes the research methodology while "Framework for developing repair process taxonomy of mechanical components" describes the framework developed for repair process taxonomy of the 


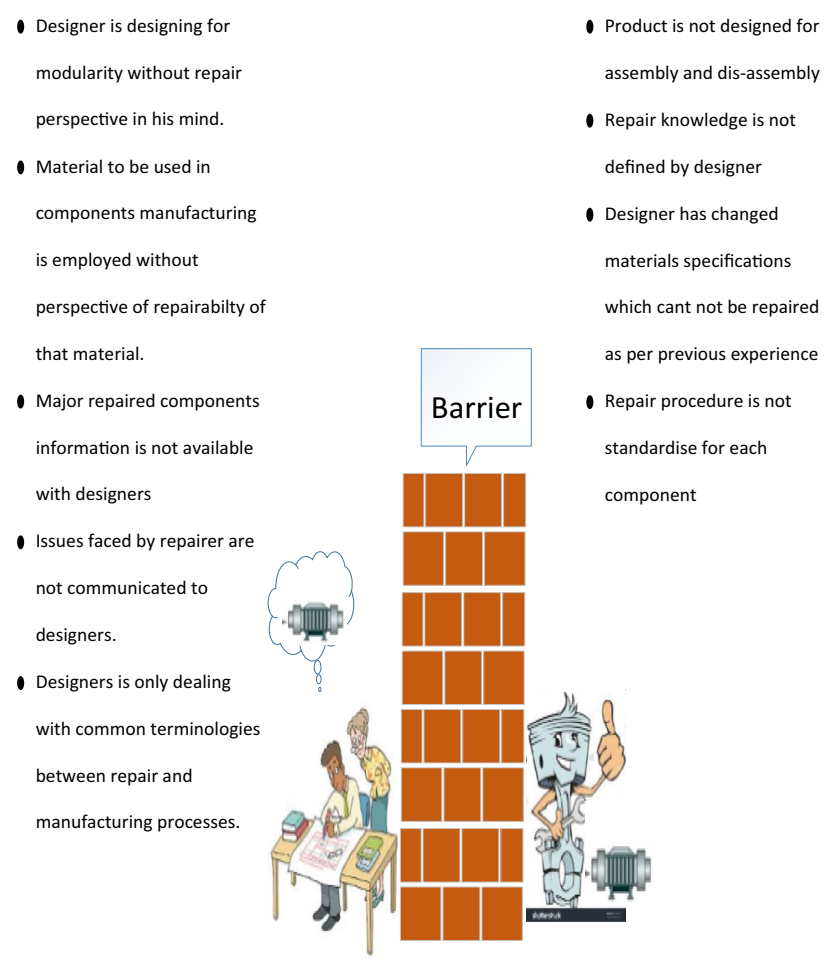

Fig. 1 Pictorial representation of issues between repairers and designers

mechanical components development. "Repair process taxonomy development method" describes the method to develop repair process taxonomy of mechanical components. "Validation through case study: development of repair process taxonomy" throws light on implementation of taxonomy development method through case study. "Final repair process taxonomy shape" discusses the conclusions that have been drawn from this research work.

\section{Literature review}

Taxonomy is the science paradigm which facilitates to improve communication, organizing structure, retrieving data rapidly and discovering new field of research in a systematic way (McCarthy 1995). Taxonomy has been developed in many fields of studies; however, biologist, library science and social science persons are considered to be the founder of taxonomy development (McCarthy and Ridgway 2000). Taxonomy has been developed in many fields including manufacturing, education, health, microprocessors, mobile applications and mathematics (McCarthy 1995; Forehand 2010; Alexander et al. 2014; Avizienis and He 1999; Nickerson et al 2009). A comparison of taxonomy development method in different fields is provided in Table 1.
Taxonomy was also developed by bloom which became famous as "bloom taxonomy" to develop a method of classification for thinking behavior that was considered to be important in learning process which concluded to three domain of taxonomy. (1) The cognitive (a knowledgebased domain having six levels). (2) The affective (altitudinal-based domain having five levels). (3) The psychomotor (skill based-domain having six levels) (Forehand 2010). In the continuation of above bloom taxonomy, bloom's digital taxonomy was developed in which domain of learning are further elaborated as low order thinking skill and high order thinking skill (Churches 2012). Taxonomy was applied in knowledge and knowledge system in organization where taxonomy was based on four criteria namely structure (how knowledge is designed and what it contain), purpose (what is knowledge for), function (what the knowledge does) and disciplinary content (Geisler 2006). Taxonomy development for knowledge management was also described in seven steps which include define requirements, identify concepts, develop draft taxonomy, review with user and SMEs (Subject Matter Experts), refine taxonomy, apply taxonomy to content and finally manage and maintain taxonomy (Whittaker and Breininger 2008). Taxonomy in the field of manufacturing was also developed in which taxonomy was created on the basis of type of process, state of work piece material, nature of processing energy (Todd et al. 1994).

Researchers have worked in the field of brazing, soldering and welding for repairing components (Boegli et al. 2002; Fried and Bögli 2002; Jhavar et al. 2013; Peças et al. 2006). Repair model for repairing components has been developed (Lee et al. 2008). Cold spray technique was employed for repairing a component (Lee et al. 2007). Product life cycle has been employed in aviation maintenance, repairing and overhaul (Lee et al. 2008) $\mathrm{CO}_{2}$ laser surfacing and arc.

\section{Literature review in repair technology}

Surfacing techniques were employed for repairing tools and micro structure on maraging steel and structural steel (Grum and Slabe 2003). Bonded repair work of components has been reviewed (Katnam et al. 2013). Thermal spraying technique was employed for repairing damaged component of stainless steel and D2 Tool steel (Tan et al. 1999). Cold spray technology was employed for repairing purpose (Champagne 2008). Composite repair of thick section was carried out (Jones and Chiu 1999). Repairing of part by laser technology was carried out (Wang et al. 2002; Borrego et al. 2009). Non-destructive inspection techniques to detect cracks were employed (Diamanti et al. 2005). Methodology for repair and overhaul of aero engine has been developed (Yilmaz et al. 2010). Ultrasonic 


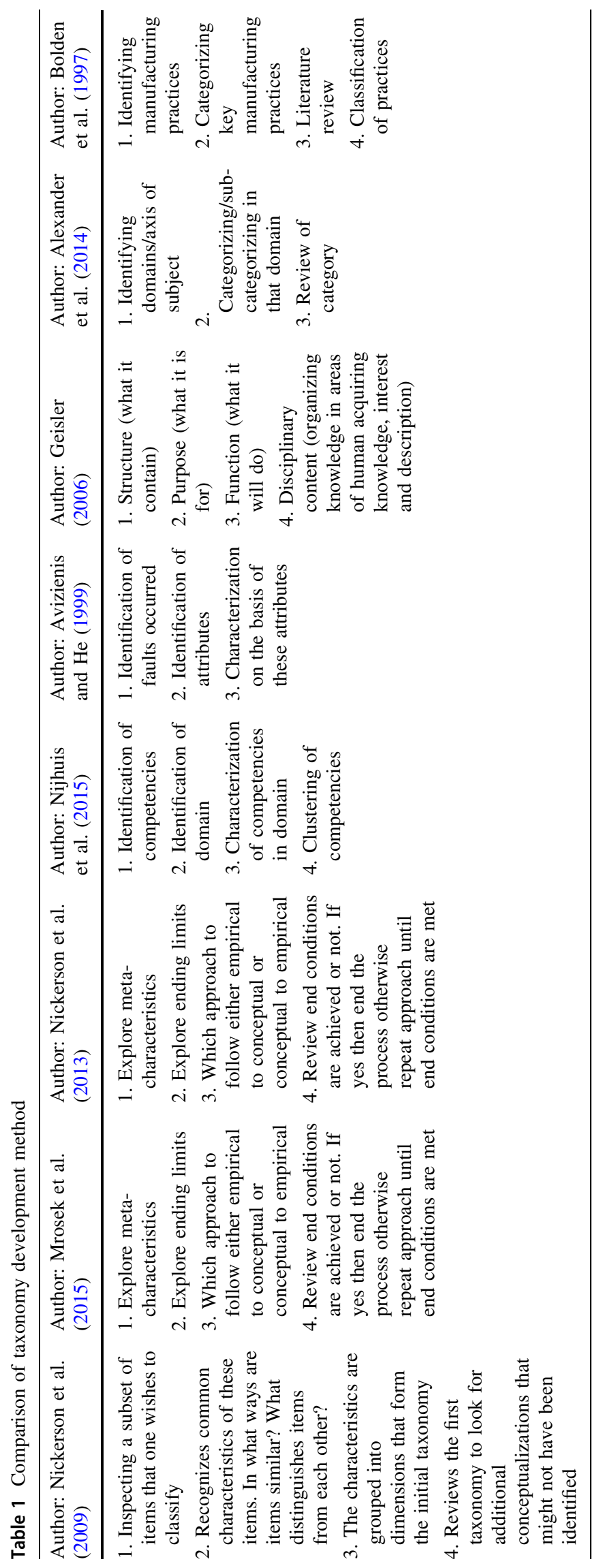


peening technology has been employed for repairing (Kudryavtsev et al. 2007). Repairing operation on different parts has been carried out (Desir 2001) but still in current scenario, no researcher is found successful in diminishing the dilemma between repair processes and manufacturing processes, for example, welding process is a joining process in manufacturing terminology but in repair terminology, welding is a material addition process to prepare surfaces which resulted in a situation where repairer are in no-man's-land. So to cater this situation, effort is being done to accumulate all the research work regarding repair on one platform, i.e. repair taxonomy, which is developed keeping in view, the repairer issues regarding repair as well as trainee entering in the repair technology. Repair taxonomy will provide repairer as well as designer with a classification, a semantic as well as a knowledge map to get rid of confusion between manufacturing and repair processes.

\section{Research methodology}

The research methodology is composed of five phases as presented in Fig. 2. It starts with understanding of taxonomy development method. Literature review is done to explore application area of taxonomy development followed by comparison of taxonomy development method and manufacturing processes adopted for repairing mechanical components in phase 1 . In phase 2 , industrial field study was

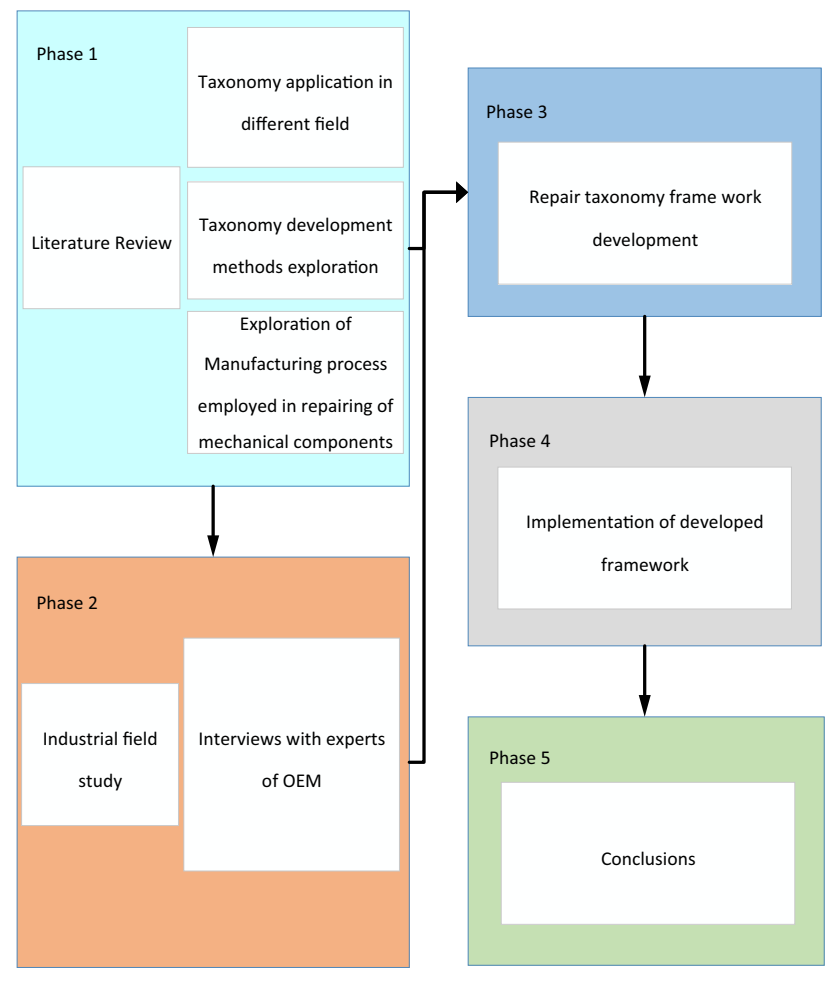

Fig. 2 Research methodology conducted and interview with experts of original equipment manufacturer was carried out for about $70 \mathrm{~h}$ approximately to identify current industrial practices and future requirements were also analyzed. In phase 3, repair process taxonomy framework was developed to provide repair designer and repair team with a solution to current issues prevailing in implementing through-life engineering business strategy. In phase 4 , implementation of above-developed frame work for taxonomy development through case will be carried out. Finally in phase 5 , conclusions that have been drawn from the research work carried out.

\section{Framework for developing repair process taxonomy of mechanical components}

\section{Taxonomy development stages}

The first stage of objective definition in developing taxonomy is to think that the objective to develop this taxonomy is to have common understanding between repairer and repair designer regarding repair processes. Output of this repair process taxonomy is to build a repair process knowledge map to the personnel belonging to repair field, i.e. repairer and repair designer so that they can easily navigate through required repair processes to develop repair scheme and to solve all the issues which are being currently faced by companies. This idea can be easily understand through scheme shown in Fig. 3. The second stage comes of analyzing the content for developing this taxonomy, i.e. Repair processes currently being employed by repairer for repairing of the component. Knowledge access will be made through literature review by assessing different researcher work in this field followed by developing a knowledge map by critical analysis of each repair process characteristics. The third stage comes of designing in which different taxonomy development concepts prevailing were identified which has been made through literature review and described in detail in "Literature review". The impact of this taxonomy must be such that it must characterize each repair process in a way that any person belonging to repair field can easily grasp the concept of repair process in a quick succession. The fourth stage comes of taxonomy development is to identify whether knowledge map developed for repair process is satisfactory or not. Will it help in developing common understanding between repairer and repair designer? The fifth stage of effectiveness evaluation to access taxonomy usefulness through expert opinion via questionnaire feedback criteria based on above mentioned attributes. Experts will be from educational sector as well as from industrial sector to get mixed point of view. These reviews were scaled in numbers to quantify feedback. 


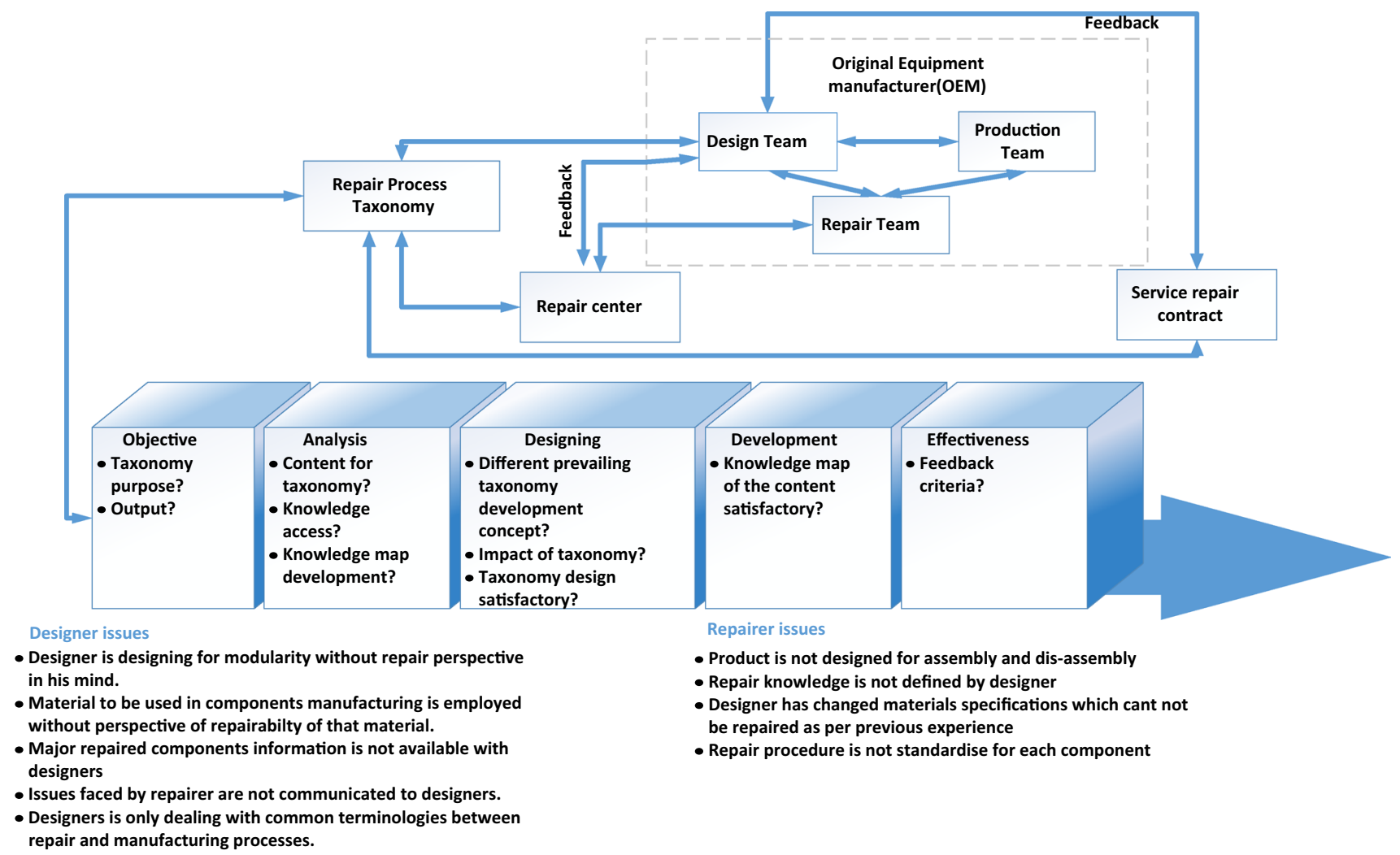

Fig. 3 Framework for repair process taxonomy development

\section{Original equipment manufacturer (OEM)}

Original equipment manufacturer (OEM) was previously dealing with repair issues by sub-contracting repair jobs but with the advent of new business strategy of providing service to customer throughout life of the customer by adopting through-life engineering concept. Since most of the repair jobs were outsourced to service repair center and repairing was mostly done by replacing worn out components by a new one at the expense of customer. Second if any major repairing of component was done at outsourced repair service center, no repair data feedback is available to the design team. So there arise a lot of issues faced by both repairer and design team. Authors have proposed a solution to these issues (Fig. 3) in order to support through life engineering concept.

Design team was previously involved in modular design so that if any part get worn out then worn out module was mostly replaced by a new one. Author suggested that modular designing must be incorporated with repair ability of that component, for example, if the shaft of water pump is designed with modularity in context of repair ability then design must be such that only worn out part of the shaft must be dismantled instead of whole shaft which will result in both cost and time saving.
Design team must select material of the components with respect to repair ability of that component so that it can be easily repair. For example, if the shaft of water pump is selected of high hardness, low weld ability then when it will be worn out after a long service life then machinability of that shaft to repair it will be difficult and weld ability to fill the cracks will be difficult, so material selection with respect to repair ability is of great importance to designers.

Major component repairing information can be made available to design team through report sharing with design team so that it will help them incorporating repair ability margin, for example, if pulley hub is designed with more thickness then when the hub and shaft arrangement get loose then hub can be machined with a sleeve fits on it to reuse it again on the same shaft.

Common terminology from manufacturing taxonomy has been used by repair centre and design team which author has tried to identify that there is a significant difference between repair process and manufacturing process. Repair processes have unique identity while manufacturing process has unique identity. Author is of the view that no development in the field of repair can take place until a general understanding of the repair processes between repairer and repair designer is being made. This dilemma can only be eliminated by 
developing repair process taxonomy for mechanical components.

When the design team will introduce modular design with repair ability then repair centre can easily assemble and disassemble components which will help them in segregating the worn out part with easy handling of that component. For example, if a heavy gear and a shaft are designed with modularity with respect to repair ability then repairer can easily disassemble worn out gear from shaft to repair it.

Since repair knowledge is not defined previously by design team as the repair job were outsourced by the original equipment manufacturer so feedback was not.

Available to designer so after adopting through life engineering concept, repairing of the component will be done at companies premises ultimately repair data will be available to the design team via consultation with repair team and service repair contractor.

When the repair knowledge will be available to the repairer with common terminologies shared between repair team and design team, standardized repair procedure can be prepared for each component to be repaired which will help in repairing job done even by medium skilled personnel. Only thing is to do is open the standardized procedure for that component and follow the step by step activity to repair that component with optimized repair processes designed by repair designer.

\section{Design, production, and repair teams}

Design team is supposed to take perform new product designing for production activities taking into account the repair data which will be made available through feedback from repair team which is composed of repair center and service repair contracts whose proposed work plan is described below. The design will coordinate both with production team and repair team to develop products incorporating repair issues encountered by repair team to implement new business strategy following through lifeengineering concept. Design team will take help from repair process taxonomy to develop common understanding of repair processes with repair center.

Production team will coordinate with design team to manufacture products incorporating repair ability concept so that product may be repaired in case of wear out with less time and cost effect. The modules proposed by author include modular design with repair ability option embedded in it. Material will be used that will be easy to repair with less time and cost effect.

Repair team will carry out repair activities at repair center with repairing issues will be feedback to design team to incorporate changes in product design to ease repairing process.

\section{Repair centers}

Repair center will perform repair activities at original equipment manufacturer (OEM) premises while sharing repair data with design team. Repair centre will take help from repair process taxonomy to develop common understanding of repair processes with design team.

\section{Service repair contracts}

Service repair contracts will be outsourced by original equipment manufacturer (OEM) only in the case that repair facility is not available or to share work load with the condition imposed that all repairing knowledge will be shared with design team which was not previously shared with design team in past causing difficulty in implementing new business strategy of implementing through-life engineering concept in its true form to enhance with its market share.

\section{Repair process taxonomy}

Repair process taxonomy will be developed with a view to bring repair team and design team on a same page regarding repair processes. Design team and repair team will take guidance from repair process taxonomy by employing repair processes having unique characteristics to design and repairing of mechanical components.

\section{Repair process taxonomy development method}

With reference to Fig. 4, during the development of repair process taxonomy, following steps were taken which include (1) meta-characteristics definition, (2) ending limits defining for iteration, (3) selecting empirical to conceptual approach or conceptual to empirical approach. If empirical to conceptual approach is selected then (4a) exploration of repair processes to be categorized is carried out. (5a) Identify characteristics of repair process (6a) grouping of repair process characteristics into one domain. If conceptual to empirical approach is selected then (4b) conceptualization of repair processes characteristics/domain is carried out. (5b) Examine repair processes under this characteristics/domain (6b) categorize these repair processes under these characteristics. (7) Checking either iteration results satisfying ending limits (Fig. 4).

In the first step of repair process taxonomy development, meta-characteristic is defined which is the root characteristic on which the taxonomy is based. When author says taxonomy is based, author is of the view that characteristics on which taxonomy is to be built will purely revolve around 


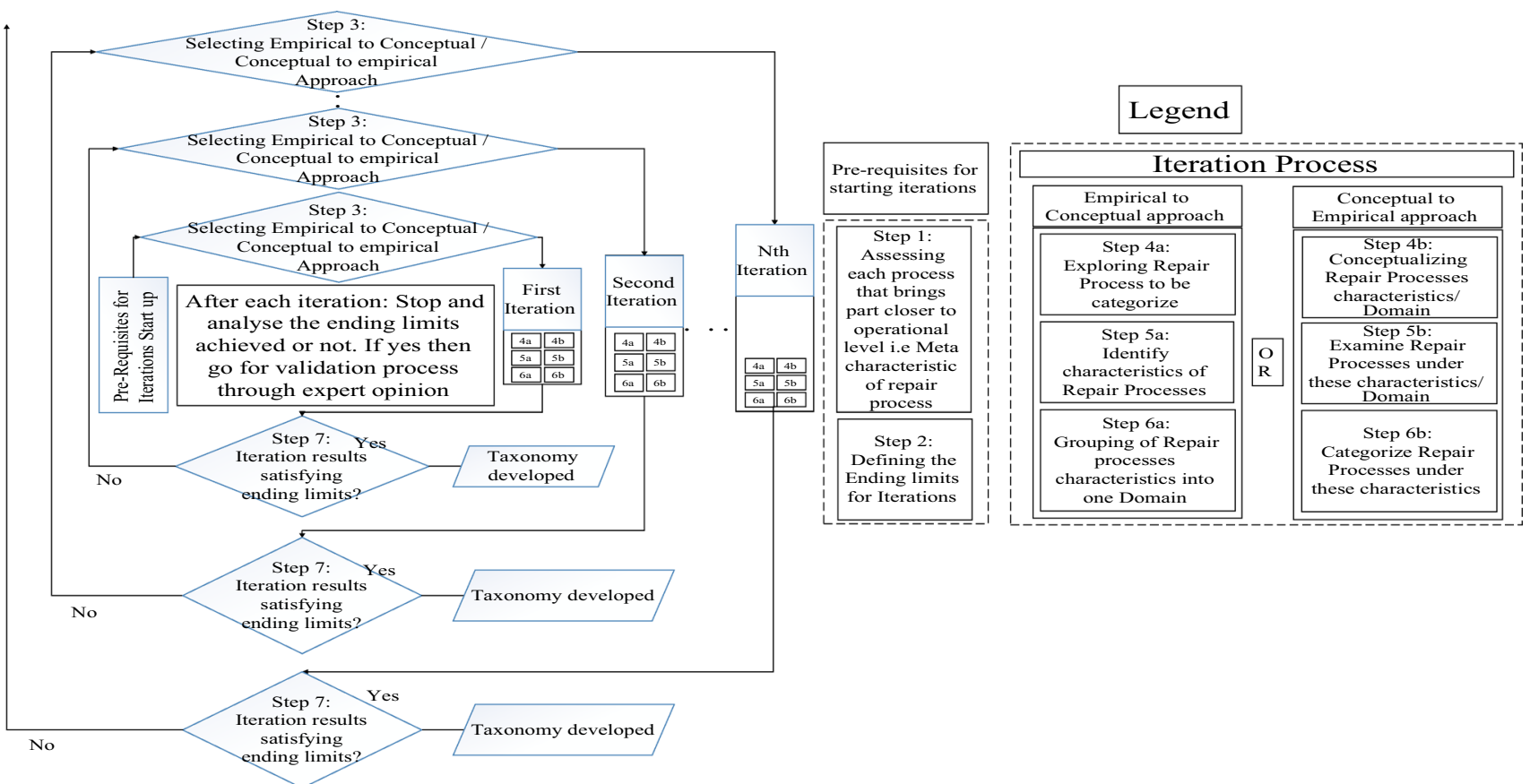

Fig. 4 Repair process taxonomy method adopted from Nickerson et al. (2013)

the meta-characteristics. Meta-characteristic actually depicts the objective of developing taxonomy. For repair taxonomy development, meta-characteristic is defined as the classifying processes which will bring damaged or worn out mechanical component closer to operational level. In the second step of repair process taxonomy development, ending limits are defined to set certain criteria for iteration process since this taxonomy developing method is based on (Nickerson et al 2009) method which is an iterative process so some boundaries are mandatory to be defined. In the third steps of repair process taxonomy development, is empirical to conceptual approach as well as conceptual to empirical approach used for taxonomy development is selected based on data type availability. In empirical to conceptual approach, fourth step is to identify characteristics of objects under consideration through literature review followed by a fifth step in which identification of characteristics of object will be done and in sixth step, grouping of these characteristics into domain will be carried out to develop taxonomy. While in conceptual to empirical approach, fourth step will be to conceptualize characteristics/domain. In fifth step, examination of objects according to characteristics and dimension conceptualized. While in sixth step, categorize these repair processes according to characteristics/domain conceptualized. In seventh step for developing taxonomy is to look for the condition specified earlier has been met or not. So after scrutiny of the whole taxonomy development process on the basis of end condition specified, a decision will be taken whether to excel further in taxonomy development or to stop it right now. If any of the ending limits specified is not yet met then taxonomy development iteration process will remain continued.

\section{Validation through case study: development of repair process taxonomy}

A. Pre-requisite for developing repair process taxonomy

(1) Step 1 (meta-characteristics) Repair process that brings part nearest to operational level.

(2) Step 2 (boundary conditions) All repair processes have been examined.

No repair process will be combined or divided in further classification in last iteration.

No characteristics of repair processes will be further added in last iteration.

No characteristics of repair processes will be combined or divided in last iteration.

Each characteristic will be unique not repeated.

B. Step 3 (approach selection) Approach: It is decided to go for Empirical to conceptual approach as some repair processes are distinguished from past research in repair area.

Iteration 1

C. Steps $4,5 \& 6$ (iteration process)

Step 4 (E2C) Following repair processes are worked out through literature review (Jhavar et al. 2013) employing manufacturing taxonomy processes to develop repair taxonomy as shown below.

Step 5 (E2C) Following characteristics of repair processes identified are listed above. 
Table 2 Taxonomy shape after iteration 1

\begin{tabular}{|c|c|c|c|}
\hline \multirow{2}{*}{$\begin{array}{l}\text { Repair } \\
\text { processes }\end{array}$} & \multicolumn{3}{|l|}{ Cleaning process } \\
\hline & $\begin{array}{l}\text { Pre-repair } \\
\text { mechanical } \\
\text { cleaning process }\end{array}$ & $\begin{array}{l}\text { Pre-repair } \\
\text { thermal cleaning } \\
\text { process }\end{array}$ & $\begin{array}{l}\text { Pre-repair } \\
\text { chemical } \\
\text { cleaning process }\end{array}$ \\
\hline $\mathrm{MC}$ & $x$ & & \\
\hline $\mathrm{TC}$ & & $x$ & \\
\hline $\mathrm{CC}$ & & & $x$ \\
\hline
\end{tabular}

1. Pre-repair mechanical cleaning

2. Pre-repair chemical cleaning

3. Pre-repair thermal cleaning

Step $6(E 2 C)$ So in this iteration step, three characteristics were identified of these repair processes which will be grouped into one domain of cleaning process to have a first shape of taxonomy.

Step 7 (ending limits achieved?) Ending limits: As there is only one dimension added in this iteration so process must be repeated. Since there are more repair processes available in literature.

The taxonomy shape after iteration 1 has been shown in Table 2. That must also be needed to consider making taxonomy concise, exploring able, more descriptive and fullbodied.

B. Step 3 (approach selection) Approach: Again it is decided to go for empirical to conceptual approach as few more repair processes have been distinguished from research in repair area.

Iteration 2

C. Step $4,5 \& 6$ (Iteration process)

Step 4 (E2C) Following repair processes are worked out through literature review (Todd et al. 1994; Jhavar et al. 2013; James et al. 2002; Kinstler 2006; Wang et al. 2002) employing manufacturing taxonomy processes to develop repair taxonomy as shown below

\begin{tabular}{ll}
\hline 1. Excavation (E) & 13. Explosive welding (EW) \\
2. Mechanical reducing (MRed) & 14. Thermal spraying (TS) \\
3. Pressure (cold) welding (PCW) & 15. Thermal welding (TW) \\
4. Friction welding (FW) & 16. Soldering (S) \\
5. Ultrasonic welding (UW) & 17. Brazing (B) \\
6. Diffusion bonding (DB) & 18. Coating (Co) \\
7. Plasma transferred arc welding & 19. Deposition \\
(PTAW) & (electroforming) (DE) \\
8. Cold spray method (CSM) & \\
9. Laser based deposition (LBD) & \\
10. Electro spark method (ESM) & \\
11. Gas tungsten arc welding & \\
(GTAW) & \\
12. Electron beam welding (EBW)
\end{tabular}

Step 5 (E2C) The characteristics of repair processes listed above were identified as explained below. Excavation process, depict the characteristics of identifying deep cracks in mechanical part to repair cracks which are in depth. Mechanical reducing is further classification of excavation process.

Pressure cold welding, friction welding, ultrasonic welding; explosive welding depicts characteristics of joining function. Gas tungsten arc welding (GTAW), electron beam welding (EBW), plasma transferred arc.

\begin{tabular}{ll}
\hline 1. Mechanical reducing (MRed) & 1.1.1d. Parting/grooving (P/G) \\
1.1. Reducing chips (RC) & 1.1.1e. Threading (SP)(T) \\
1.1.1. Single point cutting (SPC) & 1.1.2. Multi point cutting (MPC) \\
1.1.1a. Turning/facing (T/F) & 1.1.2a. Drilling (D) \\
1.1.1b. Boring (Bo) & 1.1.2b. Milling (M) \\
1.1.1c. Shaping/planning (S/P) & 1.1.2c. Filing (F) \\
1.1.2d. Sawing (S) & \\
1.1.3. Abrasive machining (AM) & \\
1.1.3a. Grinding (G) & \\
1.1.3b. Ultrasonic machining & \\
(UM) & \\
1.1.3c. Jet machining (JM)
\end{tabular}

Welding (PTAW), laser based deposition (LBD), electro spark method (ESM), thermal spraying (TS), thermal welding (TW), soldering (S), brazing (B) are all have characteristic of crack filling operation by thermal mean. Deposition (electroforming) (DE), chemical vapor phased deposition (CVPD) and diffusion bonding have a characteristic of crack filling by chemical mean and cold spray method (CSM) has a characteristics of crack filling by mechanical mean.

Step 6 (E2C) In this step, grouping of characteristics namely crack filling by thermal, mechanical and chemical mean into one domain namely material deposition process is taken place while deep crack identification process and mechanical joining are grouped in a domain namely mechanical repairing process to have second taxonomy available.

Step 7 (ending limits achieved?) Ending limits: In this iteration, two new dimensions are added with an objective to make taxonomy more concise, descriptive, explorable but still it is lacking in robustness. So it is preferable to go for next iteration as there are more repair processes available for addition to make this taxonomy more versatile. The final taxonomy shape after iteration 2 has been presented in Table 3.

B. Step 3 (approach selection) Approach: In this iteration it is decided to go for empirical to conceptual approach to extend repair processes detail. 


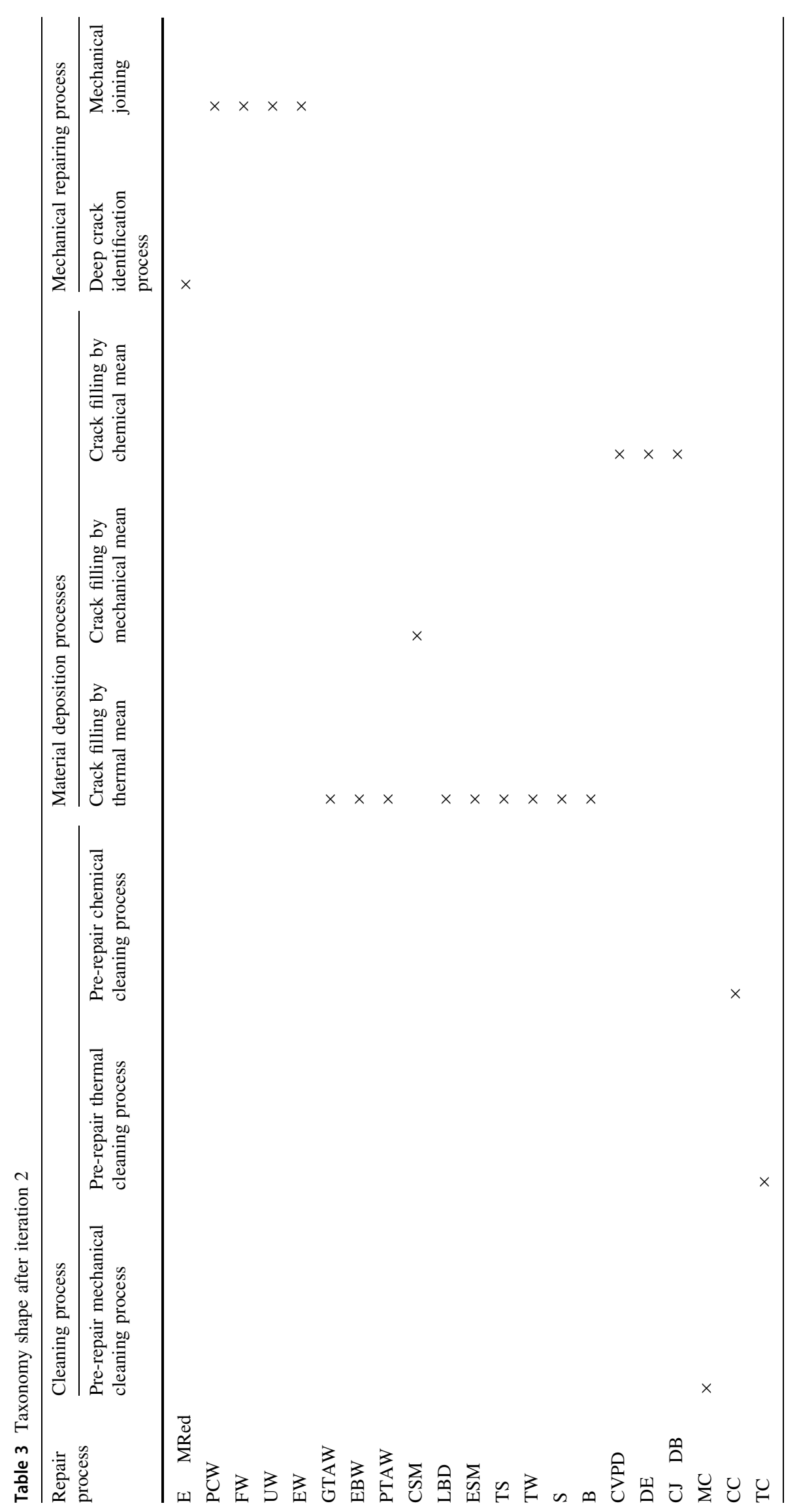




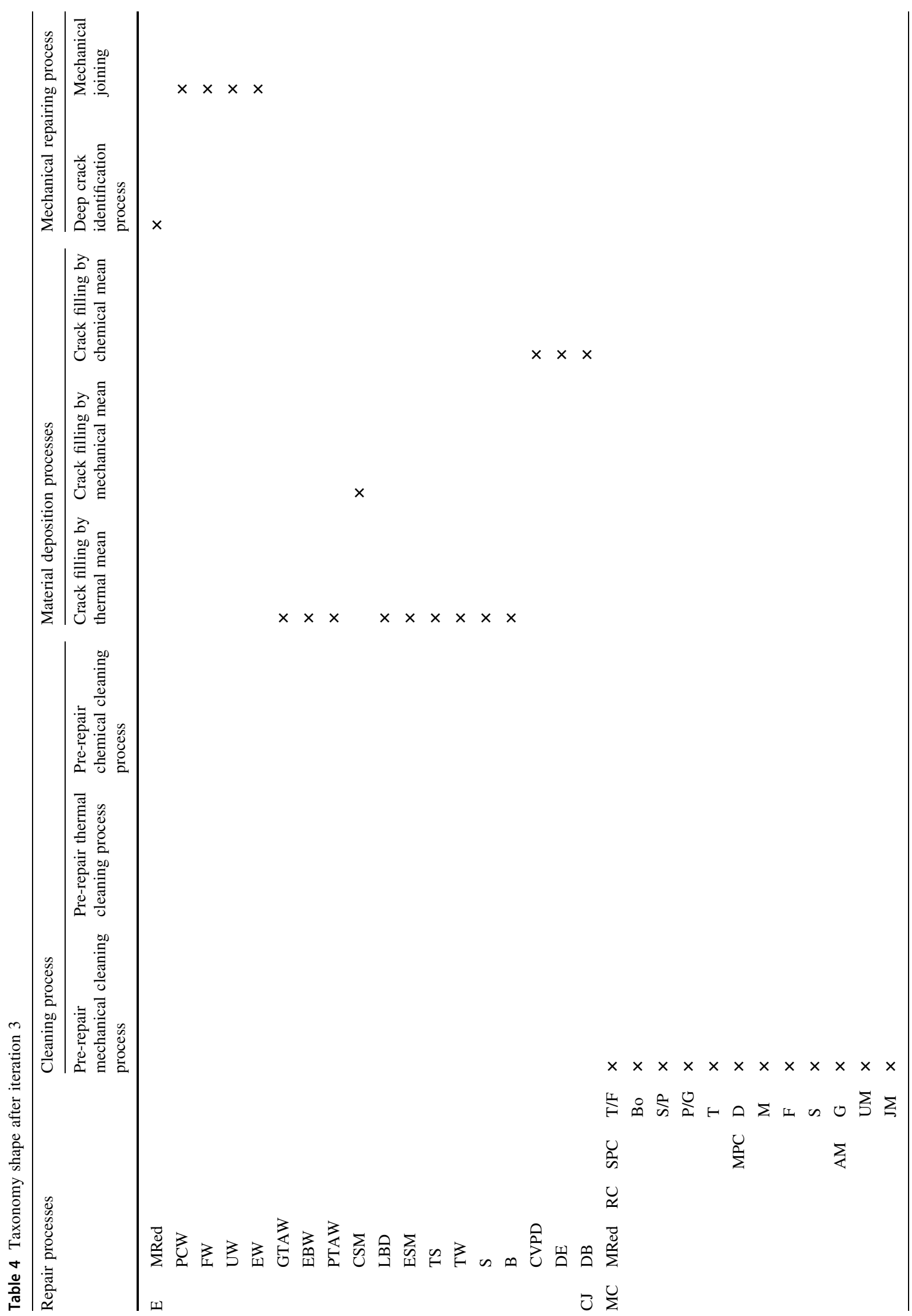




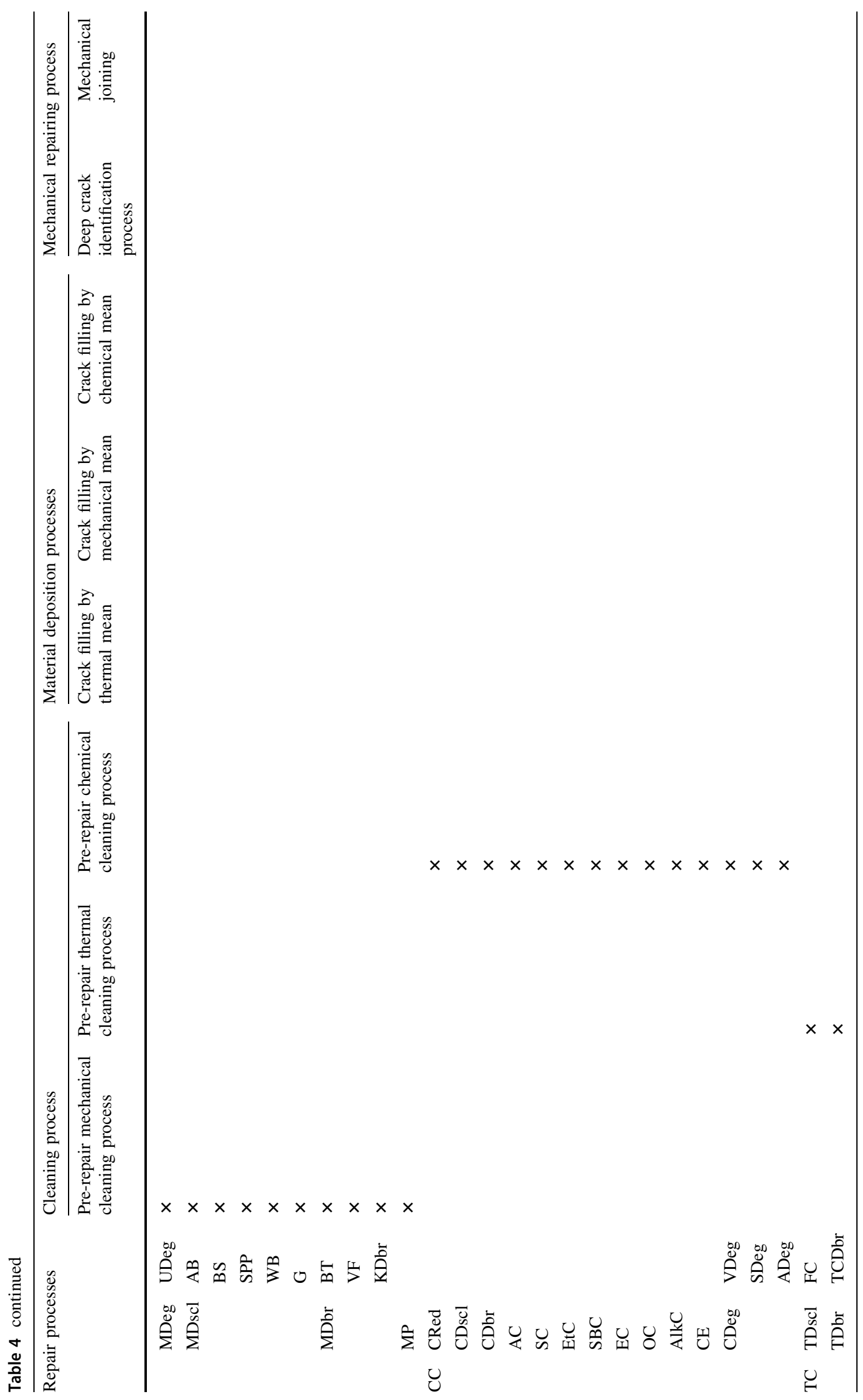




\section{Iteration 3}

C. Step $4,5 \& 6$ (iteration process)

Step 4 (E2C) Following repair processes are worked out through literature review (Todd et al. 1994; Jhavar et al. 2013; Wang et al. 2002) employing manufacturing taxonomy processes to develop repair taxonomy as shown below

Step 5(E2C) After identification of repair processes, all have characteristics of pre-cleaning mechanical process.

Step 6(E2C) All these repair processes are grouped under the pre-repair mechanical cleaning processes with no domain added.

Step 7(Ending limits achieved?) Ending limits: Since more repair processes are added in this iteration and made this taxonomy more concise, descriptive, explore able and robust but still a number of repair processes are available to make taxonomy more versatile. Table 4 depicts the final repair taxonomy after iteration 3 .

So by following this iterative method, final taxonomy shape is achieved with an objective to developed repair process taxonomy which is comprehensive, explorable and versatile in its nature.

\section{Final repair process taxonomy shape}

Final repair process taxonomy is a mixture of manufacturing process applied with a concept of repair. The detailed repair process taxonomy has been provided in Fig. 5.

\section{Conclusion}

Author has presented work in developing taxonomy in the field of repair technology as there is little or no work yet been done in this fashion. The question why this repair process taxonomy has been developed? The simple answer to this question is that taxonomy provides a complete understanding of the subject matter. Then again question arises, why there is a need to develop a thorough understanding of this repair process subject matter? The reason is that as world is progressing forward with new emerging technology in a competitive environment; customer is becoming the main focus of today's company since through-life engineering has been evolved. So in mechan-

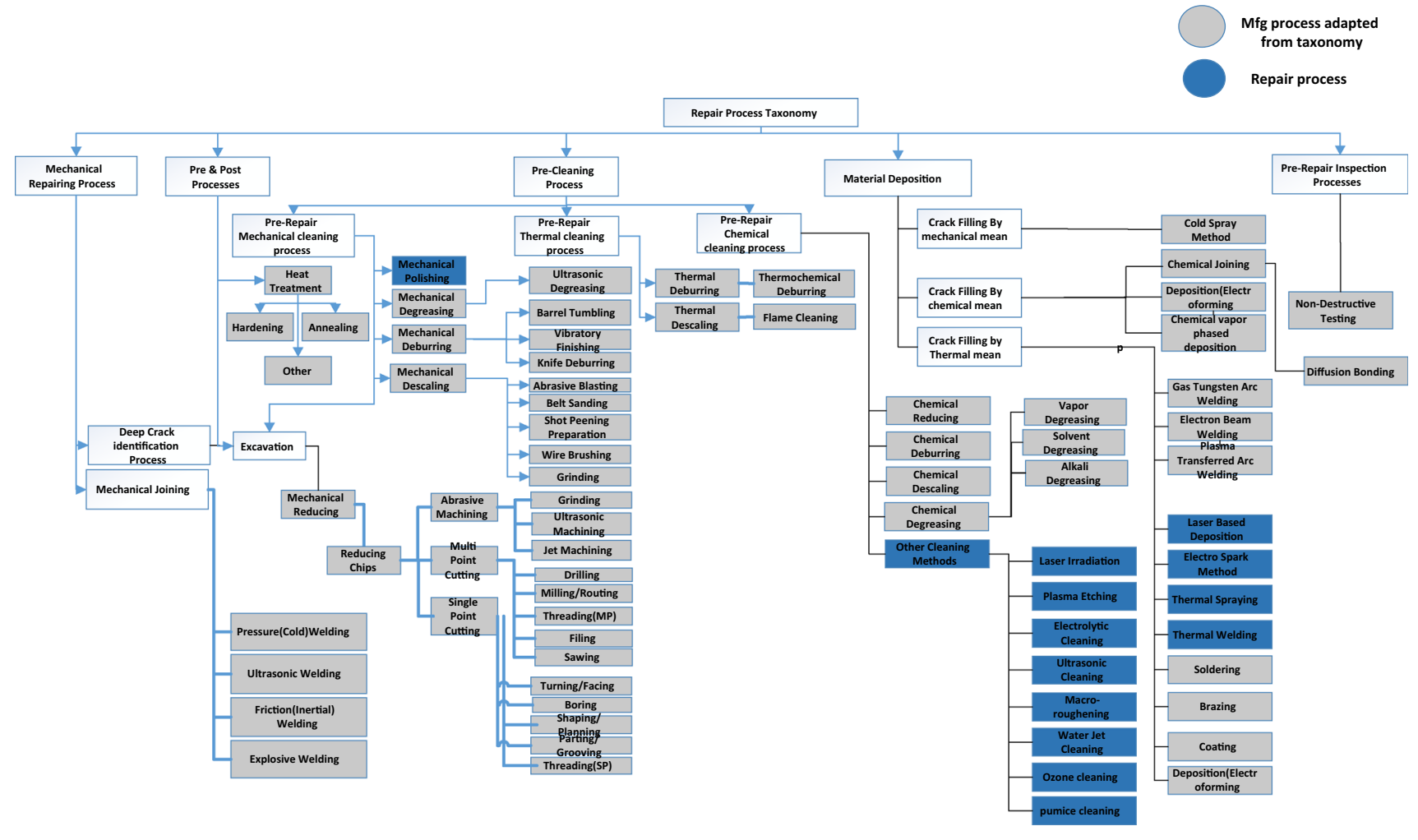

Fig. 5 Repair process taxonomy 


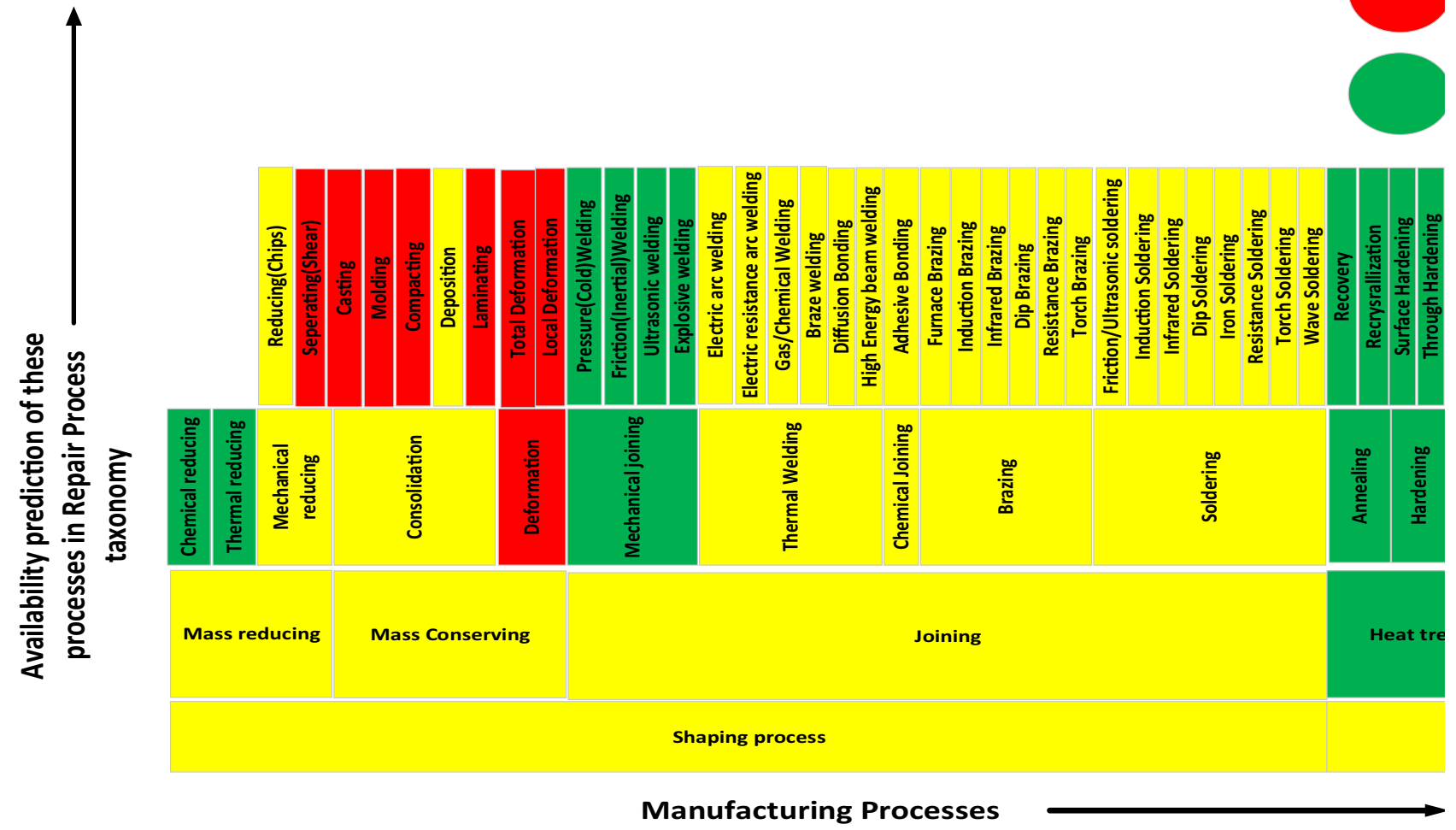

Fig. 6 Transformation from manufacturing process taxonomy to repair process taxonomy

ical field, the game is not finished by simply manufacturing the components and handed over to customer but now companies are providing services (repair) to an extended period of time to grasp customer attention, so in short companies have to be up to the mark, regarding repair services but the problem is that repairer and manufacturer are confused regarding applying of processes in context of repairing as well as in manufacturing so there is a need to draw a boundary line between repair process and manufacturing processes. Author is of the view that this problem can be solved by developing a repair process taxonomy. In developing taxonomy, literature review has been done that how different researcher have applied taxonomy to their subject matter. A very interesting thing is that taxonomy is a very liberal artifact. It is developed in a way a researcher or a user wants its subject matter classification to be. However, three approaches has been identified through literature review which different researcher applied to their objects of interest namely phenetic or numerical taxonomy, cladistics or and evolution taxonomy. The approach author followed is phenetic as author want to classify repair process on the basis of their characteristics but not on the basis of their evolutionary relationship. So a model designed to develop.

Taxonomy which is basically an improvement over Nickerson et al. (2009) model is used for developing taxonomy in Information system.

Following the frame work developed for repair process taxonomy development, meta-characteristic defined for repair processes is to the processes which brings parts closer to operation level followed by an iteration process with boundary conditions imposed to have a repair process taxonomy with six domain and eight characteristic were identified employing conceptual to empirical approach and empirical to conceptual approach. This repair process taxonomy encompasses manufacturing processes whose concept of application changes when these processes are employed in repairing of components supported by the work of researchers in the field of repair which compels author to predict scenario that has been changed as shown in Fig. 6. In this figure, the yellow color represents the manufacturing processes that have been redefined, red color demonstrates manufacturing processes that have been 
eliminated and green color represents the new processes proposed by author.

This repair process taxonomy can be employed by researcher, designer, repair team as well as new trainee repairer. Researcher can utilize this taxonomy to further extend this classification with new repair processes addition. Designer in the field of repairer can employ this repair process taxonomy to aid in developing repairing work scheme in an efficient and systematic manner. Repairer can employ this repair process taxonomy to see how much variety of repair processes can be applied to perform repairing activity of components. New trainee can easily understand the chemistry of repair processes structures and orientation of inventory of repair processes.

Open Access This article is distributed under the terms of the Creative Commons Attribution 4.0 International License (http://creative commons.org/licenses/by/4.0/), which permits unrestricted use, distribution, and reproduction in any medium, provided you give appropriate credit to the original author(s) and the source, provide a link to the Creative Commons license, and indicate if changes were made.

\section{References}

Alexander D et al (2014) The RICHE taxonomy-an innovative means of classification of child health research. Child Care Health Dev 40(5):632-639

Avizienis A, He Y (1999) Microprocessor entomology: a taxonomy of design faults in COTS microprocessors. In: Dependable computing for critical applications 7, 1999. IEEE

Boegli A, Fernihough J, Ullmann O (2002) Crack repair method, Google Patents

Bolden R et al (1997) A new taxonomy of modern manufacturing practices. Int J Oper Prod Manag 17(11):1112-1130

Borrego L et al (2009) Mould steels repaired by laser welding. Eng Fail Anal 16(2):596-607

Champagne VK (2008) The repair of magnesium rotorcraft components by cold spray. J Fail Anal Prev 8(2):164-175

Churches A (2012) Bloom's digital taxonomy. Retrieved October, 2009

Desir J-L (2001) Examples of repair welding of heavy machinery subject to breakage due to low frequency alternating stresses. Eng Fail Anal 8(5):423-437

Diamanti K, Soutis C, Hodgkinson J (2005) Non-destructive inspection of sandwich and repaired composite laminated structures. Compos Sci Technol 65(13):2059-2067

Forehand M (2010) Bloom's taxonomy. Emerg Perspect Learn Teach Technol 41:47

Fried R, Bögli A (2002) Method for repairing a gas turbine component, Google Patents
Geisler E (2006) A taxonomy and proposed codification of knowledge and knowledge systems in organizations. Knowl Process Manag 13(4):285-296

Grum J, Slabe JM (2003) A comparison of tool-repair methods using $\mathrm{CO}_{2}$ laser surfacing and arc surfacing. Appl Surf Sci 208:424-431

James AW, Wagner GP, Seth BB (2002) Cold spray repair process, Google Patents

Jhavar S, Paul C, Jain N (2013) Causes of failure and repairing options for dies and molds: a review. Eng Fail Anal 34:519-535

Jones R, Chiu WK (1999) Composite repairs to cracks in thick metallic components. Compos Struct 44(1):17-29

Katnam K, Da Silva L, Young T (2013) Bonded repair of composite aircraft structures: a review of scientific challenges and opportunities. Prog Aerosp Sci 61:26-42

Kinstler MD (2006) Repair process, Google Patents

Kudryavtsev Y et al (2007) Rehabilitation and repair of welded elements and structures by ultrasonic peening. Weld World 51(7-8):47-53

Lee J et al (2007) Repair of damaged mold surface by cold-spray method. CIRP Ann Manuf Technol 56(1):577-580

Lee $S$ et al (2008) Product lifecycle management in aviation maintenance, repair and overhaul. Comput Ind 59(2):296-303

McCarthy I (1995) Manufacturing classification: lessons from organizational systematics and biological taxonomy. Integr Manuf Syst 6(6):37-48

McCarthy I, Ridgway K (2000) Cladistics: a taxonomy for manufacturing organizations. Integr Manuf Syst 11(1):16-29

Mrosek R, Dehling T, Sunyaev A (2015) Taxonomy of health IT and medication adherence. Health Policy Technol 4(3):215-224

Nickerson R et al (2009) Taxonomy development in information systems: Developing a taxonomy of mobile applications. In: European conference in information systems

Nickerson RC, Varshney U, Muntermann J (2013) A method for taxonomy development and its application in information systems. Eur J Inf Syst 22(3):336-359

Nijhuis S, Vrijhoef R, Kessels J (2015) Towards a taxonomy for project management competences. Proc Soc Behav Sci 194:181-191

Peças P, Henriques E, Pereira B, Lino M, Silva M (2006) Fostering the use of welding technology in the mould repair. Build Future Innov

Tan J, Looney L, Hashmi M (1999) Component repair using HVOF thermal spraying. J Mater Process Technol 92:203-208

Todd RH, Allen DK, Alting L (1994) Manufacturing processes reference guide. Industrial Press Inc, New York

Wang J et al (2002) Laser aided part repair-a review. In: Proceedings of the thirteenth annual solid freeform fabrication symposium, Austin, TX

Whittaker M, Breininger K (2008) Taxonomy development for knowledge management. In: 74th general conference and council of the world library and information, Quebec, Canada

Yilmaz O, Gindy N, Gao J (2010) A repair and overhaul methodology for aeroengine components. Robot Comput Integr Manuf 26(2):190-201 